\title{
Development of the corticothalamic projections
}

\author{
Eleanor Grant, Anna Hoerder-Suabedissen and Zoltán Molnár *
}

Department of Physiology, Anatomy and Genetics, University of Oxford, Oxford, UK

\section{Edited by:}

Steffen Scholpp, Karlsruhe Institute of

Technology, Germany

\section{Reviewed by:}

Tomomi Shimogori, RIKEN Brain

Science Institute, Japan

Andre Goffinet, Catholic University of

Leuven, Belgium

\section{${ }^{*}$ Correspondence:}

Zoltán Molnár, Department of

Physiology, Anatomy and Genetics,

University of Oxford, Le Gros Clark

Building, South Parks Road, Oxford OX1 30X, UK.

e-mail: zoltan.molnar@dpag.ox.ac.uk
In this review we discuss recent advances in the understanding of corticothalamic axon guidance; patterning of the early telencephalon, the sequence and choreography of the development of projections from subplate, layers 5 and 6 . These cortical subpopulations display different axonal outgrowth kinetics and innervate distinct thalamic nuclei in a temporal pattern determined by cortical layer identity and subclass specificity. Guidance by molecular cues, structural cues, and activity-dependent mechanisms contribute to this development. There is a substantial rearrangement of the corticofugal connectivity outside the thalamus at the border of and within the reticular thalamic nucleus, a region that shares some of the characteristics of the cortical subplate during development. The early transient circuits are not well understood, nor the extent to which this developmental pattern may be driven by peripheral sensory activity. We hypothesize that transient circuits during embryonic and early postnatal development are critical in the matching of the cortical and thalamic representations and forming the cortical circuits in the mature brain.

Keywords: subplate, layer 6, layer 5, cerebral cortex, VB, LGN, reticular thalamic nucleus

\section{INTRODUCTION}

The elaborations and changes in cortical representation during evolution have been accompanied by equally impressive changes in the structure of the thalamus (Kaas, 2007). The thalamus is not merely a relay station passing on verbatim information to the cortex, rather the thalamus and cortex represent a highly integrated processing unit that dynamically regulates thalamic transmission of peripherally derived data for cortical processing (Sherman and Guillery, 1998). Layer 6 corticothalamic connectivity largely outnumbers the sensory input to the thalamus (Mitrofanis and Guillery, 1993) providing the feedforward and feedback mechanisms essential in this processing unit. Furthermore the thalamus relays layer 5 cortical output to other distal cortical areas (Guillery and Sherman, 2002), thus distributing cortico-cortical information and integrating disparate cortical areas into a global network. This network provides a substrate for the widespread synchronization of cortical and thalamic cell populations. The high frequency oscillations associated with this synchrony are suggested to underlie discrete conscious events (Steriade, 2000), highlighting the importance of layer 5-derived cortical innervation of the thalamus. As such cortical innervation of the thalamus is highly important yet its development has received little attention.

\section{THE ADULT CORTICOTHALAMIC RELATIONSHIP}

All cortical areas receive thalamic input and send projections to the thalamus (Caviness and Frost, 1980). The circuit involves three cortical cell populations and two orders of thalamic nuclei (Figure 1A). The cortical component consists of glutamatergic projection neurons residing in layers 4,5 , and 6 . First order thalamic nuclei include dorsal lateral geniculate nucleus (dLGN), ventrobasal nucleus (VB), medial geniculate nucleus (MGN), the ventrolateral nucleus $(\mathrm{VL})$, and the anterior thalamic group. These nuclei contain thalamic relay cells with specific projections that process peripheral sensory information and relay it to the cortex.
Higher order nuclei include the pulvinar group, mediodorsal thalamic group, and lateral posterior nucleus. These nuclei contain thalamic matrix cells with diffuse projections that relate corticocortical information between different cortical areas (Jones, 2002; Sherman and Guillery, 2002).

\section{NUCLEAR AND LAMINAR SPECIFICITY OF THE THALAMOCORTICAL AND CORTICOTHALAMIC CIRCUIT}

Thalamic relay cells in first order thalamic nuclei receive modality specific sensory information from peripheral nerves. All peripheral sensory information is represented in the thalamus with the exception of olfaction (which is represented indirectly via piriform cortex projection to mediodorsal thalamic nucleus; Jones, 1985). Ascending projections from thalamic nuclei are primarily directed to modality matched cortical areas, i.e., dLGN projects to primary visual cortex (V1). The target cells of first order nuclei are situated largely in layers 4 and 6 (Frost and Caviness, 1980). Collaterals from these thalamocortical axons synapse onto the GABAergic neurons residing in the reticular thalamic nucleus (RTN). These RTN neurons project to the thalamus, connecting with thalamic relay cells thus closing an inhibitory feedback loop which is involved in modulating the activity of thalamic relay cells (Jones, 2002; Cruikshank et al., 2010).

Cortical innervation of thalamic nuclei depends on the laminar identity of the cortical neurons. Layer 6 projects to the first order thalamic nuclei from which it receives input, continuing modality specificity (Figure 1B); from V1 they project to dLGN (Guillery, 1967), from primary somatosensory cortex (S1) to VB (Jones and Powell, 1968; Hoogland et al., 1987), and from auditory cortex (A1) to MGN (Diamond et al., 1969). The layer 6 axons terminate in small but numerous glutamatergic synapses on the distal dendrites of the relay cells (Guillery, 1995; Rouiller and Welker, 2000; Jones, 2002). These axons provide modulator input, modifying 


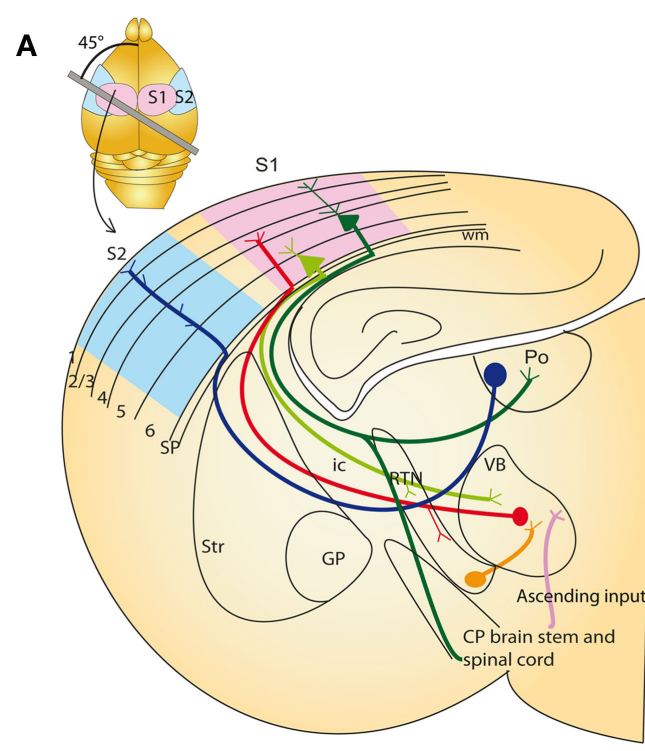

B

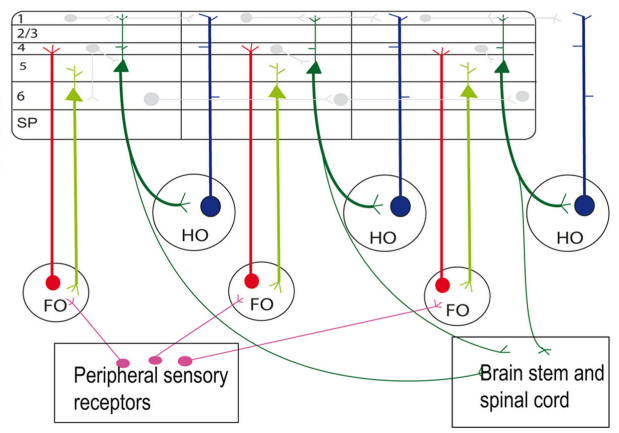

FIGURE 1 |Thalamocortical circuits in the adult on an idealized section containing somatosensory cortical connections $(A)$ and schematic representation of the two major sets of thalamic projection neurons (B). (A) Inset: outline of the mouse brain with the line indicating the plane of section to obtain thalamocortical slice containing S1 with intact thalamocortical projections. For clarity S2 cortex connectivity is also indicated in the idealized section, although a different plane of section would be required to maintain connections. Main image: coronal schematic demonstrating the specificity of the connections between the cortex and thalamus using the somatosensory system as an example. The first order VB thalamic nucleus receives somatosensory peripheral input (pink). The VB then projects axons (red) to layer 4 of the primary somatosensory cortex (S1; light blue). Layer 6 "modulator" neurons (light green) in S1 project back to the VB. Layer 5 neurons (dark green) in S1 project to subcerebral structures and make a collateral branch to a higher order thalamic nucleus, e.g., posterior thalamic nucleus (Po). The higher order nuclei then project (dark blue) to an area of cortex that is different from the one they received input from (for example S2; light pink). This projection pattern generates an open loop. (B) Schematic illustration of the possible functional circuits generated by this reoccurring open loop connectivity. Sensory information is relayed through the first order thalamic nucleus to the cortex (red). This cortical area then projects from layer 6 reciprocally back to the first order nucleus (light green). Each area is also non-reciprocally connected to a higher order thalamic nucleus. The layer 5 input to the thalamus (dark green) is an "efference copy" of the layer 5 output to the motor system in the brainstem and spinal cord. This copy is forwarded to a higher cortical area (blue). Direct cortico-cortical connections are also depicted between cortical layers and cortical areas (pale gray lines). These circuits enable cortical areas to act with other cortical areas and motor apparatus in a coordinated manner. Modified from Sherman and Guillery (2002). CP, cerebral peduncle; FO, first order thalamic nuclei; GP, globus pallidus; $\mathrm{HO}$, higher order thalamic nuclei; ic, internal capsule; RTN, reticular thalamic nuclei; SP, subplate; Str, striatum; S1, primary somatosensory cortex; S2, secondary association somatosensory cortex; Po, posterior thalamic nuclei; VB, ventrobasal thalamic nuclei; wm, white matter. thalamic relay cell activity and thus gating pathways which transmit peripheral information (Sherman and Guillery, 1998). Layer 6 axons also provide collateral projections to the RTN, generating an inhibitory feedforward circuit thus modifying thalamic relay cell activity by at least two mechanisms (Guillery, 1995; Jones, 2002).

Higher order thalamic nuclei receive the majority of their driver inputs from collaterals of layer 5 corticobulbar and corticospinal neurons (Sherman and Guillery, 2002). These layer 5 “driver" neurons synapse in large glutamatergic terminals on the matrix cells (Sherman and Guillery, 1998). The higher order thalamic nuclei then project excitatory fibers to a different cortical area than the one they received input from. These projections do not aim for layer 4, they mainly target the upper and lower layers of the cortex (Figure 1B).

\section{CONNECTIVITY ANALYSIS REVEALS COMPLEX THALAMOCORTICAL TRAJECTORY ARRANGEMENTS IN THE ADULT}

The overall relationships between thalamus and cortex follow relatively simple principles (Caviness and Frost, 1980; Behrens et al., 2003), but the fine topography is complex and not fully understood. Retinal information is represented with different polarity in the primary and secondary visual areas (Hubel and Wiesel, 1977; Rosa et al., 1997). Recording visual representations in the dLGN and primary visual cortex, Connolly and Van Essen (1984) argued that the two-dimensional visual representation has to undergo a transformation between the thalamus and the cortex in a fashion that requires the crossing of the projections in one, but not the other dimension (Connolly and Van Essen, 1984). Indeed, tracing experiments by Nelson and LeVay (1985) demonstrated exactly this arrangement (Figure 2). Paired injections of tracers revealed that thalamocortical afferent trajectories rotate in the medio-lateral, but not the antero-posterior dimension in the cat V1 in the white matter, close to their target cortex (Nelson and LeVay, 1985). Adams et al. (1997) and Molnár (1998) argued that such thalamocortical transformations are common in several cortical areas.

Corticothalamic axons also undergo temporary trajectory changes, de- and re-fasciculating and rotating around one another (Bernardo and Woolsey, 1987; Lozsádi et al., 1996). These changes are visible at the RTN and the perireticular thalamic nucleus (PRN - a population of cells lateral to the RTN), close to their thalamic target (Figure 3). 


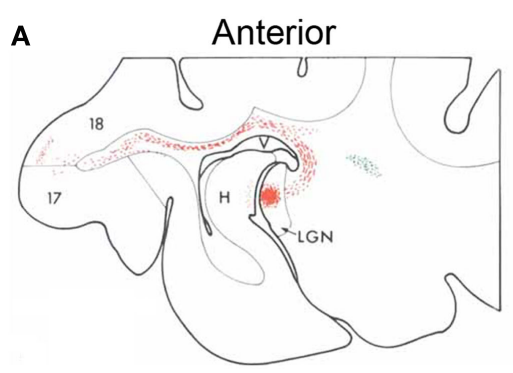

D

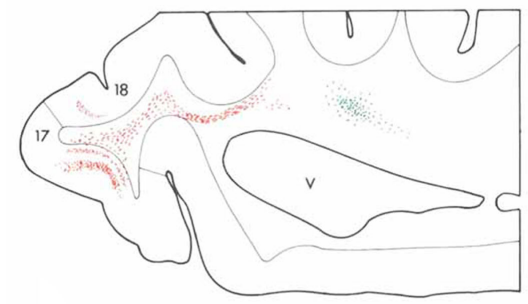

B

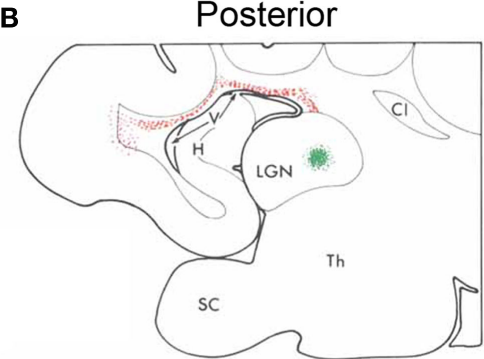

E

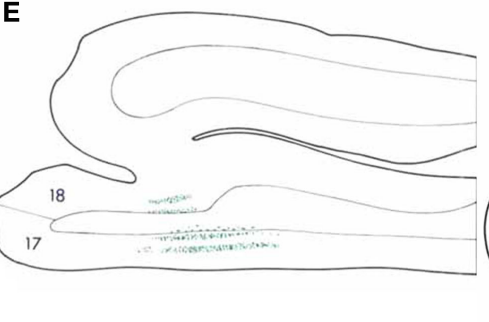

C
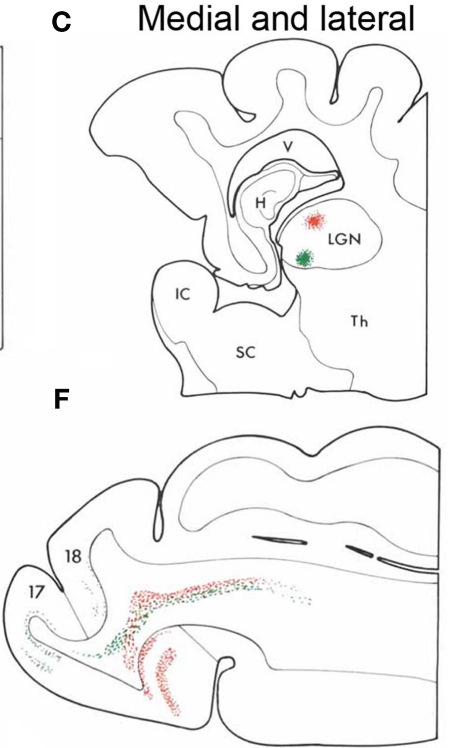

FIGURE 2 | Complex thalamocortical fiber trajectory changes in adult animals. Nelson and LeVay delivered paired injections of different tracers into the cat thalamus in an anterior and posterior $(\mathbf{A}, \mathbf{B})$ or medio-lateral arrangement (C). The tracers revealed thalamocortical projections as they leave the thalamus, traverse the optic radiation and white matter before they enter the corresponding cortical regions. The antero-posterior pairs of injections revealed no crossing of the fibers at any sector of the trajectory
(D,E), whereas the medio-lateral pairs of thalamic injections revealed fibers that crossed each other close to the primary visual cortex (F). These experiments demonstrated that lateral geniculate nucleus (LGN) afferents perform transformation in the medio-lateral, but not the antero-posterior fashion in the cat $\mathrm{V} 1$ close to the cortex in the white matter (Nelson and LeVay, 1985). Adapted from Nelson and LeVay (1985). H, hippocampus; IC, internal capsule; Th, thalamus; $V$, ventricle.

\section{DEVELOPMENTAL ESTABLISHMENT OF COMPLEX THALAMOCORTICAL TRAJECTORY ARRANGEMENTS}

Guillery and colleagues suggested that the fiber crossings observed in the region of the thalamus in the adult brain arise by rearrangements of the corticofugal projections during development (Lozsádi et al., 1996; Adams et al., 1997). Mitrofanis and Guillery (1993) suggested that during development the subcortical subplate and PRN and RTN serve as compartments where such rearrangements can occur. There are numerous similarities between these structures. Each compartment is more extensive during development than adulthood and contains largely transient cells that form part of the early circuits. Furthermore they share gene-expression patterns as demonstrated by correlation data from Allan Brain Atlas (Figures 3C,D) and comparative expression research (Montiel et al., 2011; Wang et al., 2011). Importantly during development they may act as accumulation compartments for growing fibers; thalamocortical axons accumulate in the subplate, while corticothalamic axons accumulate at the PRN and RTN. According to this hypothesis, coarse reciprocal connections are established during early development while distances are minimal. Fine-tuning of representations occurs subsequently using the two stable platforms provided by the subplate and RTN. There is anatomical and electrophysiological evidence for connections from thalamic projections to subplate neurons before the former invade the cortex. We later discuss the role of transient circuits that assist the formation and maturation of the earliest cortical circuits (Kostovic and Rakic, 1990; Allendoerfer and Shatz, 1994; Kanold and Luhmann, 2010). However, research into the corticofugal rearrangements and transient circuits at the thalamus is less established.

\section{DEVELOPMENT OF CORTICOTHALAMIC PROJECTIONS}

Thanks to improved labeling methods, time-lapse videomicroscopy and new transgenic lines that express reporter genes there has been some progress in the understanding of the earliest corticofugal outgrowth in mice. After the preplate, the earliest post-mitotic cortical neurons migrate along radial glia to the nascent preplate around embryonic day (E) 10. Before they have even left the intermediate zone (between the germinal zone and cortical plate) the cells begin extending neurites (Noctor et al., 2004; Lickiss et al., 2012). This extension continues and becomes directed, laterally, medially, rostrally, or caudally, depending on transcription factor expression. Ctip2 is highly expressed in laterally projecting corticofugals with complementary high Satb2 expression in callosal projections (Molyneaux et al., 2007; Fishell and Hanashima, 2008). These corticofugal projections extend through the intermediate zone, deep to the cortex, until they reach the lateral internal capsule between E13 and E15.5 (Auladell et al., 2000; Jacobs et al., 2007). The lateral fibers arrive first and briefly pause until dorsally derived fibers have grown the extra distance (De Carlos and O'Leary, 1992; Molnár and Cordery, 1999). At E15.5 these projections resume extension, crossing the pallial-subpallial boundary (PSPB) and entering the internal capsule. After traversing the internal capsule the axons arrive at the diencephalon-telencephalon boundary (DTB). Here the axons enter the prethalamus where they encounter the cells of the PRN and RTN at E16. Here there is a second pause in corticofugal fiber front progression until E17.5 (Molnár and Cordery, 1999; Jacobs et al., 2007). Furthermore the heterogeneous corticofugal projections are "sorted" and separated here, with some continuing to the cerebral peduncle (layer 5), and others entering the thalamus 


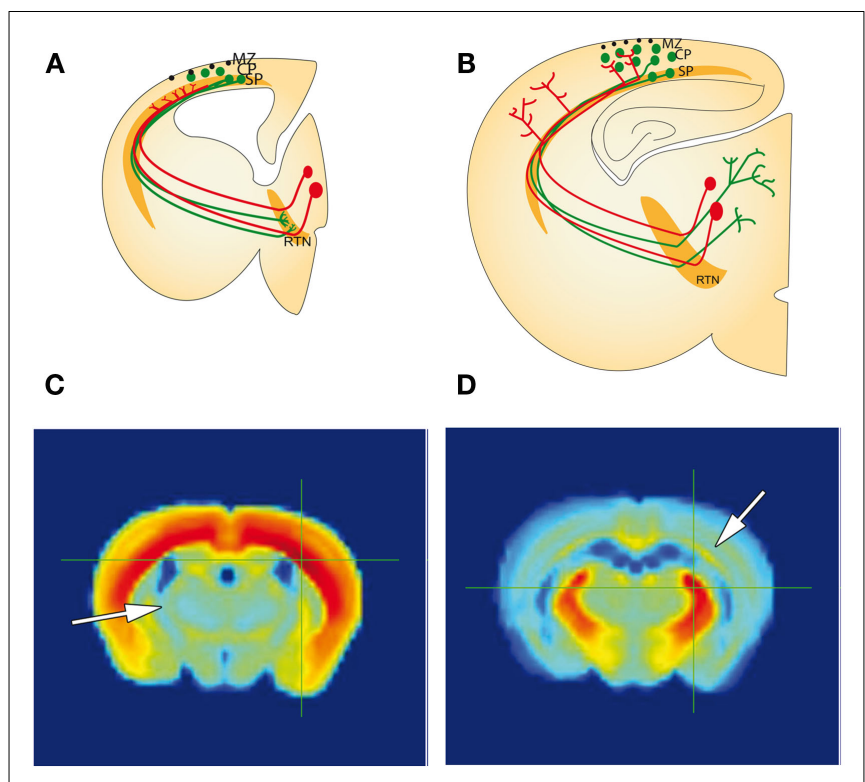

FIGURE 3 | Similarities between the cortical SP zone, and reticular thalamic nucleus during development $(A, B)$, correlated gene expression (C,D). (A) Schematic representation of a forebrain section with the developing corticothalamic connectivity. Corticofugal (green) and thalamocortical (red) axons extend toward each other at early stages during embryonic development and arrive near their targets, but both pause short of their ultimate targets. Corticofugal projections from subplate and layer 6 accumulate in the reticular thalamic nucleus (RTN) and thalamocortical projections accumulate in subplate, respectively. (B) Toward the middle of the first postnatal week corticofugal and corticopetal axons enter the thalamus and cortical plate (CP), respectively, where they arborize and establish their contacts with their ultimate targets in thalamus and neocortex. There are signs of fiber crossings in the RTN and in the subplate indicating some rearrangements during development. ( $\mathbf{A}$ and $\mathbf{B}$ modified from Montiel et al., 2011). (C,D) Gene correlation heat map from Allan Brain Atlas showing areal gene expression that correlates with expression in the SP (C) and RTN (D). The crosshairs in each figure show the region sampled for gene expression. These gene correlations show that the SP (arrow in D) has a higher gene correlation with the RTN than other subpallial structures, and the RTN (arrow in C) has a higher gene correlation with the SP than other pallial structures. This comparison is in adult, however, and during development the similarities may be even more pronounced. $\mathrm{CP}$, cortical plate; MZ, marginal zone; RTN, reticular thalamic nucleus; SP, subplate.

(layer 6 and layer 5 collaterals). The site of this sorting lies within the PRN and RTN (Mitrofanis and Baker, 1993).

\section{CORTICOTHALAMIC WAITING PERIODS}

The development and behavior of corticofugal projections has been studied with numerous methodologies, but is still not fully understood. Shatz and Rakic (1981) demonstrated with orthogradly transported tritiated proline injected into the occipital cortex of fetal rhesus monkeys that the development of corticofugal projections is synchronous with development of thalamocortical pathways, and that the corticofugal projections from V1 accumulate outside the lateral geniculate nucleus (LGN) for a protracted period (Shatz and Rakic, 1981). This suggests a similar "waiting period" for the corticothalamic projections outside the thalamus as the "waiting period" for the thalamocortical projections as they arrive at the cortex (Rakic, 1976). The exact timing and pattern of the early subplate, layer 6 and layer 5 fibers projecting subcortically and entering the thalamus is still not established. Waiting periods (in temporal order of fiber tract progression) have been demonstrated in the white matter or lateral internal capsule in ferrets (Clascá et al., 1995), in the RTN (Molnár and Cordery, 1999) and outside the LGN in monkey (Shatz and Rakic, 1981). A recent transgenic mouse line expressing tau-eGFP in subplate and layer 6 projections demonstrates two waiting periods, the first as the fiber front reaches the lateral internal capsule and a second as it arrives at the DTB. These mixed origin tau-eGFP fibers enter the thalamus in a clear temporal sequence depending upon the thalamic nucleus to be innervated (Jacobs et al., 2007). However, it has been debated whether subplate projections ever enter the dorsal thalamus (Allendoerfer and Shatz, 1994).

\section{LAYER-SPECIFIC INGROWTH INTO THE THALAMUS}

After the second waiting period at the RTN corticothalamic axons shift orientation once more and invade the thalamus, a process that takes several days with most thalamic nuclei being innervated postnatally in rats, mice, and hamsters (Miller et al., 1993; Molnár and Cordery, 1999; Jacobs et al., 2007). The innervation of the thalamus in mammalian species occurs in a temporal pattern which correlates with the functional establishment of behaviors associated with relevant sensory systems. Somatosensory and motor functions mature before visual and auditory functions; the somatosensory VB, and motor ventrolateral nucleus, are innervated earliest between E18.5 and P0.5, auditory MGN and visual dLGN are not fully innervated until P8 (Molnár et al., 1998a; Jacobs et al., 2007).

The three corticothalamic projection populations grow toward the thalamus with distinct temporal patterns; however which cortical layer reaches the thalamus first is contested within the literature. Subplate neurons are well placed to pioneer the course and could provide structural guidance to layer 5 and 6 axons. In support of this hypothesis, there are several species in which the first axons to reach the lateral internal capsule do so before the cortical plate cells become post-mitotic, therefore indicating that the projections arise from the earlier-born subplate cells in mice, rats and cats (McConnell et al., 1989, 1994; De Carlos and O'Leary, 1992; Molnár and Blakemore, 1995; Molnár et al., 1998a,b; Jacobs et al., 2007). Furthermore, in cats, ablation of subplate cells with timed kainic acid administration leads corticothalamic axons to fail to connect with appropriate thalamic nuclei (McConnell et al., 1994).

This, however, does not identify the temporal order in which subplate, layer 6 and layer 5 collaterals invade the thalamus. In hamsters, Miller et al. (1993) used retrograde carbocyanine dye tracing to assess timed invasion of the thalamus. At birth (postnatal day - P0) a limited number of layer 6 and subplate axons are back-labeled by thalamic DiI. This is quickly followed at P3 by the large ingrowth of layer 5 axons. The prevalence of layer 5 axons in the thalamus remains only until P7 at which point layer distribution reverses again (Miller et al., 1993). However similar tracing experiments in ferrets produced slightly different temporal patterns, demonstrating instead that layer 5 axons arrive in the thalamus several days before deeper layers (Clascá et al., 1995).

Thus the exact timing of each cortical layer's arrival is currently unresolved and may differ in different species. Combining these 
results suggest that whilst subplate projections leave the cortex first, layer 5 projections may be the first to innervate thalamus, followed by layer 6 . It is tempting to speculate that the extra time taken by subplate axons is a result of some rearrangement of representation during this period. How this rearrangement is controlled during the waiting period, or whether it is modulated by the input from the sensory periphery is not yet understood. The layer-specific timing of cortical innervation to the thalamus suggests future work should address questions of waiting period differences; do both layer 5 and layer 6 undergo the same waiting periods or does one population wait whilst the other forges ahead?

\section{RECENT ADVANCES USING REPORTER GENE EXPRESSING LINES}

The inability to label subplate, layer 6 and layer 5 neurons and their neurites selectively, hinders our understanding of the developmental integration of these neurons into the intra- and extra-cortical circuitry. This is now rapidly changing. Due to the advances in molecular taxonomy of cortical neurons, we have more tools to analyze circuits (Molnár and Cheung, 2006; Molyneaux et al., 2007; Hoerder-Suabedissen et al., 2009). These tools include subplate specific transgenic GFP animals, the Lpar1-eGFP (formerly Edg2eGFP) mouse, the Golli-tau-eGFP mouse, and the CTGF-eGFP mouse (Jacobs et al., 2007; Hoerder-Suabedissen and Molnár, 2012b) (Figure 4). These mice express GFP primarily in the subplate. Below we present our work characterizing the subplate cells labeled in these animals.

Co-localizing GFP with neuronal and subplate markers revealed distinct, although overlapping, subpopulations within the subplate (Hoerder-Suabedissen and Molnár, 2012b). These subpopulations display different patterns of growth into the thalamic nuclei (Figure 5). Lpar1-eGFP fibers have not reached the RTN by $\mathrm{P} 2$. By P6 GFP+ fibers have entered VB in a pattern which suggests they innervate the hollows of the barreloids. No fibers have entered the LGN. By P14 the VB and LGN have been innervated.

In contrast Golli-tau-eGFP cortical fibers have different growth kinetics. At P2 the GFP+ fiber front is at the RTN and many fibers can be seen clearly entering VB. By P6 the fibers have fully entered $\mathrm{VB}$ and are patterned in the septa between barreloids. At this age the dLGN is not innervated, however, the first fibers are accumulating between VB and the ventral edge of the dLGN. At P14 the GFP+ fibers have innervated VB in the hollows of barreloids. The dLGN is now completely innervated although the vLGN is not (Figure 5).

Retrograde carbocyanine dye tracing at P8 demonstrates only $7 \%$ of the cells back-labeled from the thalamus are GFP+ in the Lpar1-eGFP mouse whereas 50\% of back-labeled cells are GFP+ in the Golli-tau-eGFP mouse (Figure 6).

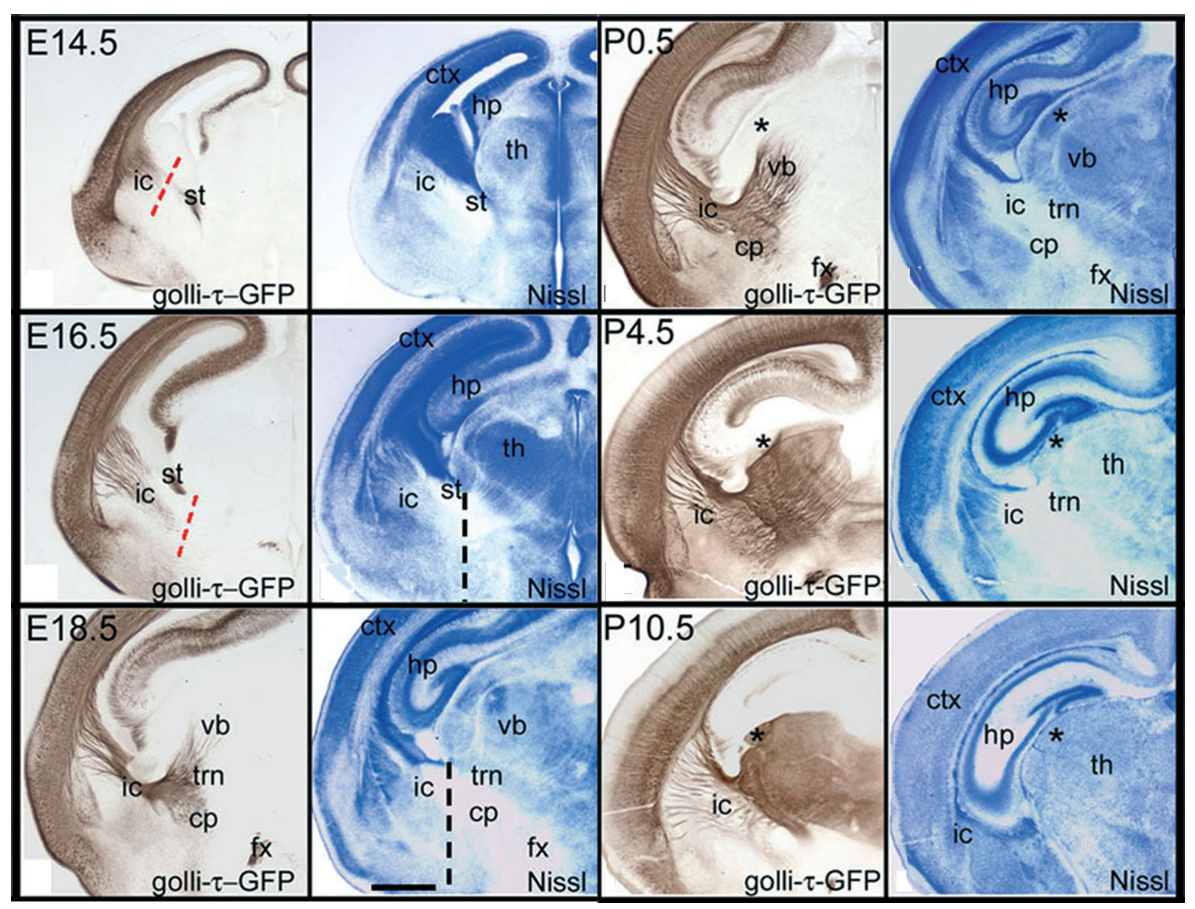

FIGURE 4 | Temporal pattern of subplate (layer $6 \mathrm{~b}$ ) cortical axons ingrowth to the thalamus of the GTE mouse. Adapted from Jacobs et al. (2007). The Golli-tau-eGFP mouse has GFP labeling in the axons of deep cortical layer axons, mostly in layer 6 and subplate. Visualization of these fibers demonstrates the growth of cortical axons toward the thalamus during development. At E14.5 cortical axons have reached the lateral cortex, but only a few have crossed the PSPB. By E16.5 the cortical fibers have reached the internal capsule and advanced toward the RTN (labeled TRN in panels), which they reach by E18.5. Between P0 and P4 cortical axons innervate the midline nuclei, but they advance relatively slowly and some thalamic nuclei (e.g., dLGN - asterisk) do not get a substantial innervation until the end of the first postnatal week. dLGN, dorsal lateral geniculate nucleus; GP, globus pallidus; LGE, lateral ganglionic eminence; MD, mediodorsal nucleus; MGE, medial ganglionic eminence; PSPB, pallial-subpallial boundary; RTN, reticular thalamic nucleus; Stri, striatum; VB, ventrobasal nucleus. 


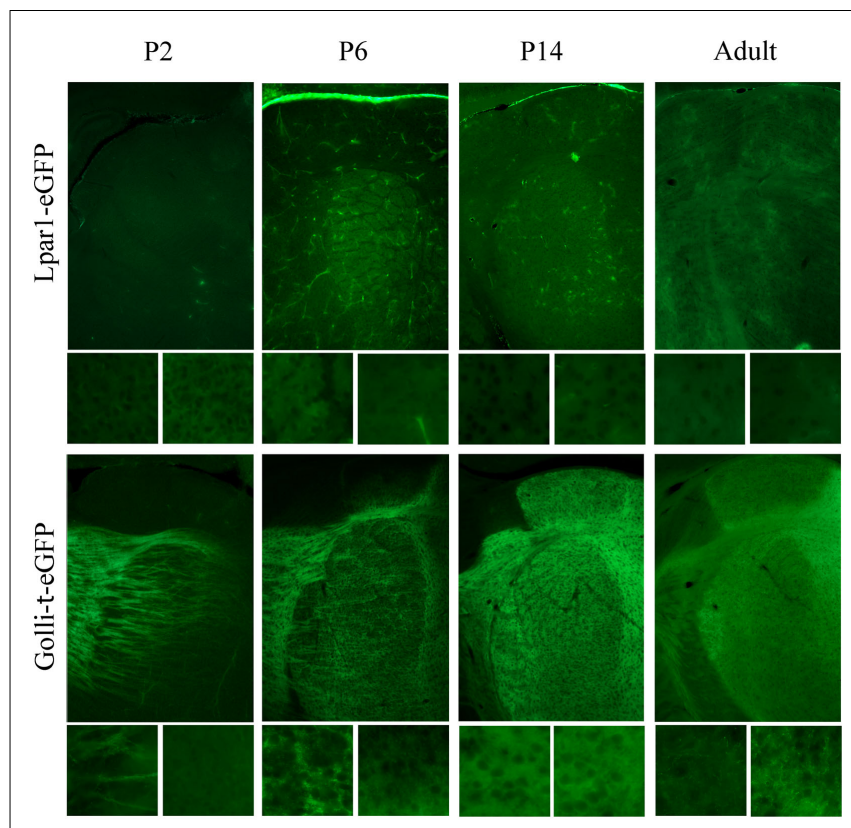

FIGURE 5 |The developing innervation of the thalamus by subpopulations of subplate neurons. Cortical sections, dorsal at top of image, lateral at left of image. Boxes beneath each image show higher magnification of the VB (left) and dLGN (right). Characterization of transgenic mouse lines Lpar1-eGFP and Golli-tau-eGFP identify clearly distinct, although overlapping, subpopulations of subplate neurons on coronal section of thalamus. These distinct populations innervate the thalamus with a different temporal pattern. At P2 Lpar1-eGFP fibers have not reached the RTN. By P6 GFP+ fibers have entered VB in a barreloid pattern. No fibers have entered the LGN. By P14 VB and LGN have been innervated. In the Golli-tau-eGFP the GFP+ fiber front is at the RTN and many fibers can be seen clearly entering VB at P2. By P6 the fibers have fully entered VB and are patterned in the septa between barreloids. The $\mathrm{dLGN}$ is not yet innervated however GFP+ fibers accumulate between VB and the ventral edge of the dLGN. At P14 the Golli-tau fibers have innervated VB in the hollows of barreloids. The dLGN is now completely innervated although the $v L G N$ is not. $d L G N$, dorsal lateral geniculate nucleus; RTN, reticular thalamic nucleus; VB, ventrobasal nucleus; VLGN, ventral lateral geniculate nucleus.

Thus GFP+ fibers in each transgenic line exhibit distinct temporal patterns for entering the thalamus, project to the thalamus in different numbers, and upon entering establish a different pattern of innervation.

Our results demonstrate that not only does layer identity determine distinct ingrowth kinetics - but subpopulations of cells within layers also display specific properties of thalamic ingrowth.

\section{MOLECULAR AND CELLULAR MECHANISMS OF CORTICOFUGAL DEVELOPMENT DEVELOPMENTAL GENE-EXPRESSION BOUNDARIES}

The early telencephalon is subdivided by the differential expression of genes including Pax6 and Gsh2 (Schuurmans and Guillemot, 2002). These gene-expression patterns generate distinct neural subpopulations and give rise to the regional patterns encountered by the corticofugal axons. These regions generate a complex genetic and structural landscape which provides cues for corticothalamic axons to navigate with.

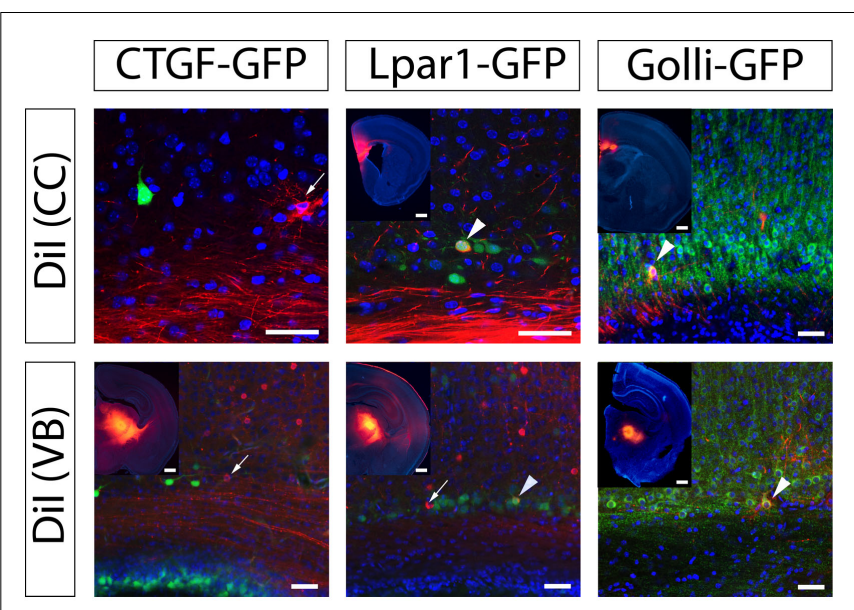

FIGURE 6 |Three subplate subpopulations have distinct projection profiles. Cortical sections, dorsal top of image, lateral is left of image. Dil back-labeling from the VB or the CC demonstrate that CTGF-eGFP labeled subplate cells are rarely-to-never back-labeled from distant structures suggesting they project locally. Insert shows Dil crystal position. The Lpar1-eGFP subpopulation is back-labeled from corpus callosum and VB; $7 \%$ of Dil+ cells from VB are Edg2-GFP+ ( $n=745$ cells $)$ and $26 \%$ of Dil+ cells from CC are Edg2-GFP+ ( $n=114$ cells). The Golli-tau-eGFP subpopulation is also back-labeled from corpus callosum and VB; $50 \%$ of Dil+ cells from VB are Golli-tau-eGFP+ ( $n=65$ cells), and $33 \%$ of Dil+ cells from CC are Golli-tau-eGFP+ $(n=45$ cells). VB, ventrobasal thalamic nucleus; CC, corpus callosum.

\section{THE PALLIAL-SUBPALLIAL BOUNDARY}

The PSPB is a key region during corticothalamic and thalamocortical development; there are numerous mutants which present axon guidance defects at the boundary (López-Bendito and Molnar, 2003). The PSPB (see Figure 7) extend along a graduated overlapping gene-expression domain separating the developing cortex from the striatum (hence its alternative name - the corticostriatal boundary). It is primarily generated and maintained by opposing gradients of Pax6 and Gsh2 expression. Pax6 is highly expressed in the dorsal pallium and conversely, Gsh2 is highly expressed in the subpallium (Carney et al., 2009). The dorsal pallium, which gives rise to excitatory cortical neurons, additionally expresses Tbr1, Emx1, and Ngn2. The subpallium expresses additional ventral organizers such as Mash1, Dlx2, and Nkx2.1 and generates inhibitory cortical interneurons and ventral telencephalic cells (Simeone et al., 1992; Stoykova and Gruss, 1994; Puelles et al., 2000). Within these subdivisions there are further discrete gene expression gradients differentiating the dorsal, lateral, and ventral pallium, and, within the subpallium, also differentiating the dorsal and ventral lateral ganglionic eminence, and the medial ganglionic eminence (Schuurmans and Guillemot, 2002; Figure 7).

The PSPB is an important decision point where early corticofugal projections turn sharply from their original ventrolateral trajectory to a medial one to enter the subpallium (Agmon et al., 1995; Molnár and Cordery, 1999). Early patterning of the pallium and subpallium by organizer genes including Pax6 and Gsh2 determines expression patterns of later guidance molecules. Pax6 is especially important for the generation of the PSPB. In Pax6 

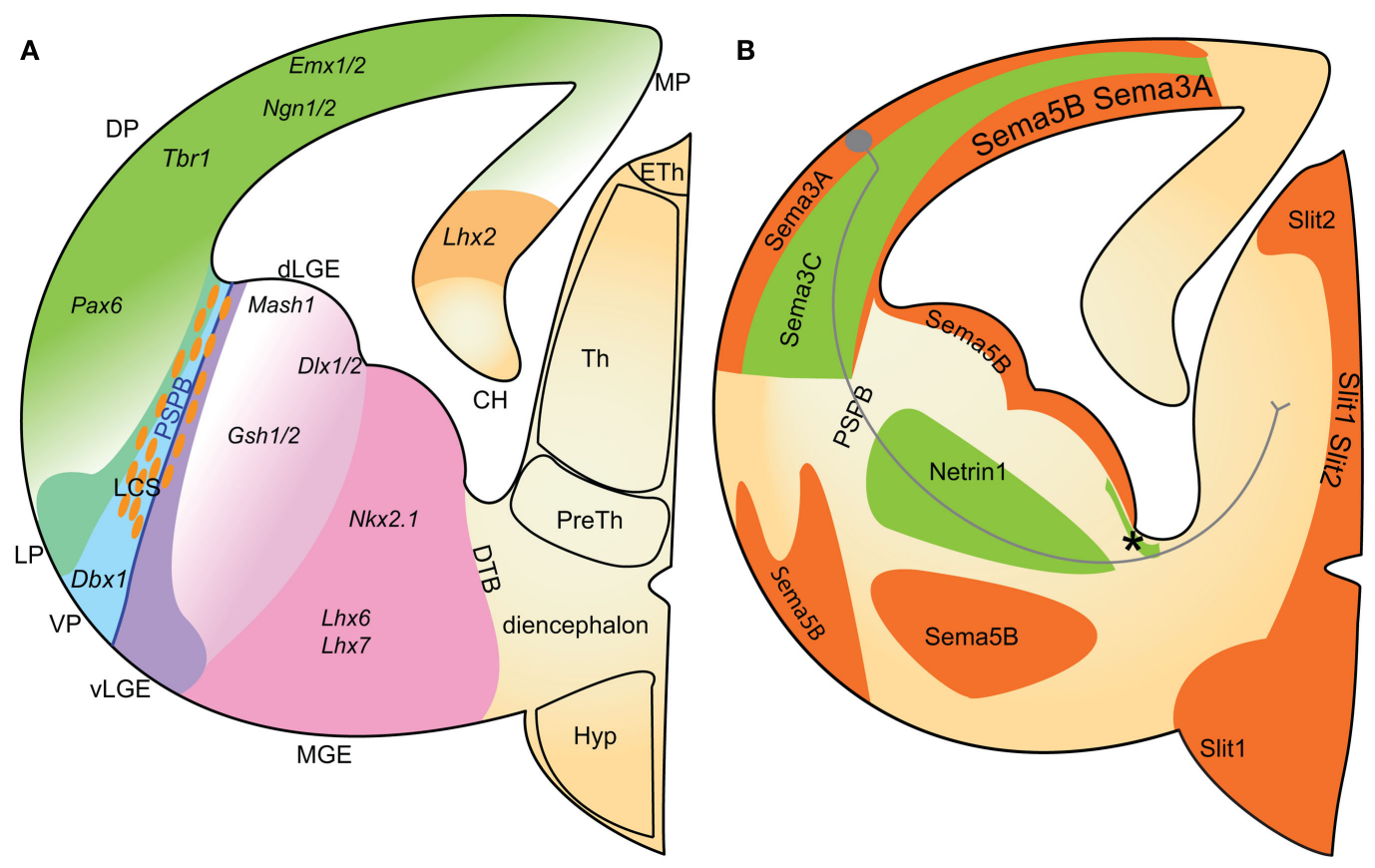

FIGURE 7 | Schematic representation of gene-expression boundaries in the developing telencephalon (A) and the expression patterns of identified axon guidance cues in relation to corticothalamic axons (B). (A) Early gene-expression boundaries subdivide the developing telencephalon into the pallium, in dorsal telencephalon, and the subpallium in the ventral telencephalon. The pallial-subpallial boundary lies between opposing gradients of Pax6 and Gsh2 expression in the pallium and subpallium respectively. Further subdivisions are generated with other discrete gene gradients. Dorsal pallium (DP) progenitors express Pax1, Emx1/2, and Ngn1/2 (green gradient). Proximal to the cortical hem, the medial DP progenitors express Lhx2 (yellow). Ventral pallium (VP) progenitors express Dbx1 (aqua/turquoise). Within the subpallium, dorsal lateral ganglionic eminence (dLGE; pink gradient) progenitors express Mash 1 and DIX1/2 and have higher expression of Gsh $1 / 2$ than ventral LGE cells (light purple). The MGE can be distinguished from LGE by expression of Nkx2.1, Lhx6, and Lhx7 in the MGE (pink). The lateral cortical stream cells (LCS; orange cells) migrate along radial glia at the PSPB. (B) Corticothalamic axons encounter combinations of molecular guidance cues as they navigate toward the thalamus. Chemoattractant Sema3C (labeled green) is expressed in a lateral to medial gradient in the intermediate zone. Netrin-1 is expressed in the internal capsule (labeled and asterisk). Within the thalamus, chemoattractive guidance cues for corticothalamic axons have not yet been identified. Corticothalamic chemorepulsive cues include Sema3A, Sema5B, Slit1, and Slit2 (orange). Combinations of chemorepellents are expressed in a pattern that flanks the route of corticothalamic axons. The positions of the pallial-subpallial and diencephalon-telencephalon boundaries are also represented. $\mathrm{CH}$, cortical hem; dLGE, dorsal lateral ganglionic eminence; DP, dorsal pallium; DTB, diencephalon-telencephalon boundary; LCS, lateral cortical stream; LP, lateral pallium; MGE, medial ganglionic eminence; MP, medial pallium; PSPB, pallial-subpallial boundary; VP, ventral pallium; vLGE, ventral lateral ganglionic eminence.
LacZ knock-out mice the expression of corticofugal guidance cues Netrin-1, Sema3C, and Sema5A is disrupted (Jones et al., 2002). Furthermore the PSPB may be the site of a temporary physical barrier. The lateral cortical stream (LCS) is formed at the PSPB by ventrolateral migration of a heterogeneous population including Pax6+, pallium-derived and Dlx2+, subpallium-derived cells (Carney et al., 2006; Carney et al., 2009). This migratory stream, along a palisade of radial glia, may generate a physical boundary preventing axons from crossing into the subpallium until there are appropriate cues or a physical bridge becomes available. Evidence for this hypothesis is provided by the $\mathrm{Pax}^{-/}$mouse strain, where corticothalamic axons fail to cross the PSPB, most misrouting ventrally and following the current of the LCS. The few fibers that succeed in crossing do so in abnormally large fascicles (Hevner et al., 2002; Jones et al., 2002). Pax6 ${ }^{-1-}$ mice have a higher cellular density at the PSPB suggesting the mutation may increase the LCS thus enhancing a normal anatomical barrier and preventing crossing (Jones et al., 2002; Piñon et al., 2008). This physical barrier may be overcome by time dependent mechanisms such as axon-axon fasciculation, thus enabling precise temporal control of corticofugal guidance. Indeed this is supported by recent work showing thalamic axons require cortical axons in order to cross the PSPB, discussed in more detail later (Chen et al., 2012; Molnár et al., 2012).

\section{THE DIENCEPHALON-TELENCEPHALON BOUNDARY}

The DTB lies antero-laterally to the thalamus and prethalamus. The genetic identity of this boundary is much less clearly established than the PSPB and it is identified solely by nearby anatomical landmarks including the prethalamus dorso-posterior to it (López-Bendito and Molnar, 2003; Garel and Rubenstein, 2004; Hanashima et al., 2006). Close to DTB, within the internal capsule, there are turning points where corticothalamic axons reroute dorsally to invade thalamus and other corticofugal axons start their descent through the cerebral peduncle to the brainstem and spinal cord (Mitrofanis and Baker, 1993; Agmon et al., 1995; Lozsádi et al., 1996). This region appears important for sorting subpopulations of cortical projection neurons according to their target destination. 
The DTB may also have similar barrier functions to the PSPB. Disruption of pioneer axons or fasciculation with thalamic axons prevents corticothalamic axons from entering the diencephalon or invading the thalamus correctly (McConnell et al., 1994; Hevner et al., 2002).

These developmental gene-expression boundaries contribute to corticothalamic guidance in three ways. (1) Generating physical boundaries that can be appropriately permissive or restrictive depending on developmental stage. (2) Acting as decision points for major trajectory changes. (3) Setting up important patterns of guidance molecules. The full extent of the contribution to guidance that these developmental gene-expression boundaries make is still under investigation. As is the importance of the temporal choreography of the development of functional corticothalamic circuits (Molnár et al., 2012).

\section{STRUCTURAL GUIDANCE CUES}

Since the first description of the early corticofugal axon front extending toward the thalamus (McConnell et al., 1989) a possible role of structural guidance cues in thalamocortical axon guidance has been postulated. These ideas were formulated as the "Handshake Hypothesis" (Blakemore and Molnar, 1990; Molnár and Blakemore, 1995; Molnár et al., 1998a,b), which suggests that early corticofugal and thalamocortical projections meet at the PSPB and the early corticofugal projections aid the thalamic fibers to cross through this region toward the cortex. The relationship between early corticofugal and thalamic projections has been debated. It has been suggested that they fasciculate with each other in internal capsule and intermediate zone (Molnár and Blakemore, 1995; Molnár et al., 1998a,b); but other studies suggest that they run in separate compartments (Miller et al., 1993) or interdigitate only in a restricted portion of their path (Bicknese et al., 1994). Some of these issues are related to the difficulties of delivering paired tracers into the equivalent regions of the cortex and the thalamus. The Golli-tau-eGFP mouse model (see above) demonstrates the intimate association of early corticofugal projections with thalamic afferents (Piñon et al., 2005) from the intermediate zone, PSPB and also throughout the lateral sector of the internal capsule.

Several mutants with thalamocortical guidance defects also display aberrant development of corticofugal projections (Hevner et al., 2002; López-Bendito and Molnar, 2003). Mutation of the thalamic gene Gbx2 causes a reduced projection of thalamocortical axons into the internal capsule. Subsequently, corticothalamic axons fail to enter the diencephalon from the subpallium, thus suggesting that thalamic axons provide some cue to corticothalamic axons that may include physical fasciculation to help them cross the DTB (Hevner et al., 2002). Recent research has demonstrated that structural support from populations of other axons can be crucial to crossing early developmental gene boundaries (Chen et al., 2012). When cortical fibers are absent and thus do not provide structural support at the PSPB, thalamic axons in Em $\times 1^{\text {cre }}$; $A p c^{\text {loxp/loxp }}$ mouse fail to reach the cortex although the mutant cortex remains attractive to the thalamic fibers (Chen et al., 2012). The authors demonstrate that the phenotype can be rescued by the replacement of cortical fibers across the PSPB. As such the use of structural support from other fiber populations to cross gene boundaries is important and may be contributing to cortical crossing at the DTB.

Due to a better understanding of forebrain patterning and the availability of conditional knock-outs, there is a recent revival of focus on structural guidance cues to overcome physical barriers in the telencephalon. Zhou et al. $(2008,2009)$ have demonstrated that region specific Celsr3 inactivation affects development of the internal capsule in different ways. In Celsr3|Foxg1 mice the internal capsule is defective and thalamic axons either cross to the contralateral diencephalon or descend to the ventral surface of the telencephalon. In Celsr3|Dlx5/6 mice, the internal capsule is also abnormal and thalamic fibers are misrouted to the amygdala. Furthermore, the early corticofugal axons fail to advance toward the thalamus, and instead stop at the PSPB, forming a mass resembling an amputational neuroma. In Celsr3|Emx1 mice, the internal capsule is intact and there are normal thalamocortical connections (Zhou et al., 2008).

The molecular and cellular nature of these interactions is not understood. This limits the interpretation even in these conditional knockouts. The cell surface proteins involved in fasciculation have not been identified and it appears bidirectional signaling as well as just fasciculation may be important for axonal guidance (Hevner et al., 2002).

\section{CORRIDOR CELLS}

Early work on corticothalamic development identified a population of cells in the internal capsule, the perireticular cells of the PRN. Their position coincides with the point where corticothalamic axons deflect dorsally into the prethalamus and where layer 5 axon branches are sorted to project to thalamus or to subcerebral targets (Mitrofanis and Baker, 1993). These cells were previously suggested have a role in guiding the corticothalamic axons given the major rearrangement behavior upon reaching them (Mitrofanis and Guillery, 1993).

Since then a second population of cells named corridor cells, derived from the lateral ganglionic eminence, have been demonstrated to generate a critical permissive corridor, within the restrictive medial ganglionic eminence (MGE) (López-Bendito et al., 2006). Without these cells thalamocortical axons are repelled by MGE and fail to properly navigate to the cortex. These cells may also be required to generate a permissive substrate for cortical axons to grow across similar to their support of thalamic axons. Furthermore back-labeling has suggested these cells may overlap with the perireticular neurons and so may contribute to guiding corticothalamic axons and sorting layer 5 thalamic and subcerebral projections. This will become apparent with further research.

\section{MOLECULAR GUIDANCE CUES}

Recent advances have identified major families of well-known guidance molecules in the guidance of corticothalamic axons (Figure 7B).

Members of the semaphorin family provide several early, context dependent cues, and mutations of these genes generate subtle phenotypes suggesting multiple cues collaborate at each stage of guidance. Corticofugal axons are repelled from Sema3A expressing cortical plate and attracted toward the Sema3C expressing intermediate zone (Bagnard et al., 1998, 2001; Skaliora et al., 1998). 
The intermediate zone forms a permissive lane between the cortical plate and the ventricular zone as Sema3A, along with Sema5B, prevents cortical axons overshooting into the cortical germinal zone (Bagnard et al., 1998; Lett et al., 2009). Sema3A also attracts cortical dendrites. The asymmetric distribution of cellular guanylate cyclase enables different responses of cortical axons and dendrites to Sema3A (Polleux et al., 2000).

The lateral-to-medial gradient of Sema3C attracts corticothalamic axons extending within the intermediate zone toward the lateral cortex (Bagnard et al., 1998, 2000). The complementary medial-to-lateral gradient of expression of Sema3A in the ventricular zone may also repel corticofugal axons coming from the medial cortex.

Chemoattractant Netrin-1 is expressed in the internal capsule and ventral telencephalon. This is complementary to Dcc expression (Netrin-1 attraction receptor) in corticothalamic axons (Oeschger et al., 2011). In vitro, Netrin-1 mediates long range attraction to E12.5 and E13.5 corticothalamic axons (Métin et al., 1997; Richards et al., 1997). This attraction can induce turning and therefore appears responsible for corticofugal growth cone reorientation toward the ventral telencephalon (Métin et al., 1997). Chemorepulsion may also guide turning due to Sema5B expression in the lateral cortex flanking the route of axons that cross the PSPB (Skaliora et al., 1998; Lett et al., 2009).

Ensuring that axons remain within the internal capsule involves several chemorepulsive interactions. During development Sema5B expression in the germinal zones of the ganglionic eminences and the globus pallidus borders the corticothalamic path through the internal capsule (Skaliora et al., 1998; Lett et al., 2009). Corticothalamic explants are repelled by Sema5B expressing cells and ectopic Sema5B in the internal capsule causes cortical axons to stall at the new Sema5B boundary. Furthermore RNA interference against Sema5B causes aberrant entry of cortical axons into the germinal zones (Lett et al., 2009). Thus Sema5B restricts the growth of cortical axons to their appropriate trajectory.

Inhibitory cell surface molecules Slit1 and 2, and receptors Robol and 2, also mediate the guidance of the corticothalamic axons within the ventral telencephalon and diencephalon. Slit1 and 2 are expressed in overlapping domains including the ganglionic eminences, prethalamus, hypothalamus, and the germinal zone of the dorsal thalamus (Braisted et al., 2000). Robol and 2 are expressed in complementary patterns in the cortical plate, intermediate zone, and dorsal thalamus (López-Bendito et al., 2007). In Slit 2 mutants, Slit 1 and 2 double mutants, and Robo 1 and 2 double mutants corticothalamic guidance is disrupted with the majority of corticofugal fibers continuing ventrally instead of turning at the PSPB, some reaching the basal telencephalic surface. Those which do correctly enter the ventral telencephalon then aberrantly cross the ventral midline (Bagri et al., 2002; López-Bendito et al., 2007).

Slit pathway components therefore ensure containment of corticothalamic axons within the internal capsule and direct corticothalamic axons dorsally upon reaching the DTB in order to enter the thalamus rather than crossing the midline (Bagri et al., 2002; López-Bendito et al., 2007; Braisted et al., 2009).

Guidance cues, which direct axons from specific cortical regions to the thalamic nuclei that they connect to in adulthood, are yet to be elucidated; however candidate cues are beginning to be identified. Using microarrays, Sur and colleagues identify gene-expression differences between the LGN and MGN. Axon guidance molecules including Ephs and ephrins, semaphorins, slits and netrin pathways were differentially expressed between the two nuclei (Horng et al., 2009). Furthermore cues EphA7 and Ntrk2 expression is up-regulated in both the LGN and the rewired MGN, in which after peripheral ablation of auditory nerves, the ingrowing retinal axons invade the MGN and the LGN. Thus distinct guidance cue expression may contribute to the specific neural connectivity between thalamic nuclei. Indeed a review in this research topic proposes the hypothesis that overlapping molecular expression in the thalamus may be responsible for the determination of areal axon guidance from thalamus to the cortex (Price et al., 2012). These overlapping and combinatorial gene-expression patterns may also be responsible for organizing cortical axon guidance into specific thalamic nuclei.

Molecular control of temporal dynamics such as the waiting periods has proved harder to elucidate although recent discoveries are beginning to suggest answers. Robol is expressed by corticothalamic neurons. It appears to act as a molecular slowing signal as $R o b o 1^{-/}$corticothalamic axons reach their targets a day early (Andrews et al., 2006). It appears this slowing signal is not mediated by the canonical Slit-Robo interaction as Slit2 and Slit 1 and 2 double mutants have a different phenotype in which most corticothalamic axons fail to reach the thalamus rather than being delayed and Slit1 mutants do not have corticothalamic phenotypes (Bagri et al., 2002).

Signals that might cause different waiting periods for distinct populations of corticothalamic axons are currently unclear. Guidance pathway molecules, including Unc5c, differ between the subplate and lower cortical plate (Oeschger et al., 2011). Unc5c is a receptor which mediates repulsion to soluble Netrin-1. It is transiently up-regulated in subplate cells compared to layer 5/layer 6. This up-regulation coincides temporally with the first waiting period that corticofugal fibers undergo (E14.5 in mouse). Unc5c has been demonstrated to produce a waiting period during the guidance of primary sensory axons to the spinal cord (Watanabe et al., 2006).

Switching responses to Netrin 1 requires cortical axons to alter their molecular expression after crossing the PSPB. Fluctuating expression of guidance cue receptors over time allows a population of axons to grow through different compartments and only respond to relevant cues. We suggest a temporal pattern of receptor expression as seen with Unc5c may generate the waiting periods and specific temporal growth patterns. Furthermore differential expression of guidance cue receptors between populations of corticothalamic axons generates specific responses of each population to each cue. We propose such molecular differences may generate different waiting behavior in corticothalamic axon populations. Once layer-specific waiting periods are recognized this may provide insight into how temporal control helps cortical neurons path-find to the correct thalamic nucleus.

Many major molecular cues guiding corticothalamic axons have been identified. Complex combinations of various cues generate the specific and detailed connectivity patterns that characterize the connections between cortex and thalamus.

There are likely to be many more, and subtler, cues involved in the precise details of the developmental events. For example cortical layer-specific competency to respond to guidance 
cues has not been addressed. Future work should determine cortical layer-specific or even neuronal subtype specific ingrowth to understand the relevance of the stage and subtype specific innervation of different thalamic nuclei by axons from particular cortical areas. Selective subplate, layer 6 and layer 5 gene expression profiling at the time of major decisions in axon growth would help to resolve some of these issues. Furthermore greater understanding of the sequence of circuit formation might give insight into self-organizing mechanisms during development. In addition to molecular cues there may be an activity related component although so far no phenotype has been described in various SNARE complex knock-out mice mutant (Washbourne et al., 2002; Molnár et al., 2002) or cocultures (Blakey et al., 2012). Furthermore evidence so far has shown no phenotype of early corticothalamic innervation in the Golli-taueGFP mouse after peripheral manipulations (Grant and Molnár, 2012).

\section{UNDERSTANDING TRANSIENT CIRCUITS IN CORTEX}

The role of transient circuits involving subplate neurons has been demonstrated in the developing visual cortex during ocular dominance formation (Ghosh et al., 1990) and orientation column formation (Kanold et al., 2003) in carnivores. Similar mechanisms might operate in the barrel field of the mouse primary somatosensory cortex (Piñon et al., 2009; Tolner et al., 2012). Thalamic axons reach the intermediate zone and subplate several days prior to innervating the cortex. During this accumulation of thalamic axons, layer 4 exhibits di-synaptic activation in response to thalamic fiber excitation suggesting that thalamic axons synapse with the subplate neurons that synapse onto layer 4 neurons. After 2 days thalamic activation of cortical layer 4 neurons is monosynaptic reflecting direct thalamic innervation (Zhao et al., 2009). Furthermore subplate ablation in cats stops normal up-regulation of glutamate receptor subunit, GluR1, in cortical dendrites thus leading to reduced strength at the thalamocortical synapse (Kanold et al., 2003). Selective ablation of subplate beneath limb or barrel cortex in rat confirms these results; ablation abolishes spontaneous and evoked spindle burst activity in limb cortex in vivo and thalamocortical connections to layer 4 are weaker than controls in vitro (Tolner et al., 2012). Therefore this early developmental feedforward innervation via the subplate is proposed to strengthen and stabilize the developing thalamic to layer 4 synapses.

This transient circuit also regulates maturation of cortical inhibition and ocular dominance columns. Subplate ablation disrupts neuronal receptor profile maturation. Cortical neurons fail to up-regulate KCC2 channel expression. Without KCC2 neurons maintain high internal chloride concentrations and GABA receptor activation continues to depolarize, rather than hyperpolarize, the membrane (Kanold et al., 2003). The loss of proper cortical inhibition causes paradoxical effects on ocular dominance columns; subplate ablation causes monocular deprivation to favor the deprived eye (Kanold et al., 2003; Kanold and Shatz, 2006). By adulthood the subplate circuit is transformed or dismantled, a large proportion of the early born subplate neurons have died (Price et al., 1997; Hoerder-Suabedissen and Molnár, 2012b), but some survive into adulthood as layer $6 \mathrm{~b}$.
We have little understanding of the mode of integration of subplate neurites into the cortical plate prior, during, and after thalamic innervation. Axonal and/or dendritic remodeling associated with thalamocortical ingrowth and periphery related patterning has recently been demonstrated by studies of single cell morphology (Hoerder-Suabedissen and Molnár, 2012a,b). The establishment of area-specific thalamocortical connections is also considered to be dependent on early circuits involving subplate neurons (Molnár and Blakemore, 1995; Catalano and Shatz, 1998; Shimogori and Grove, 2005). Shimogori and Grove (2005) demonstrated that thalamocortical projections could be shifted to different cortical areas by manipulating cortical gene-expression patterns. The site of these shifts was identified in subplate and white matter.

\section{UNDERSTANDING TRANSIENT CIRCUITS IN THALAMUS}

The interactions between the early corticofugal projections and the PRN and RTN are even less understood. A critical question which remains to be addressed is how corticothalamic axons integrate into functional circuits with thalamic and reticular (RTN) neurons.

The potential role of transient circuits in cortical connections to the thalamus has not been probed. As discussed previously the subplate shares many similarities with the PRN and RTN. These largely transient populations of cells, subplate and PRN, contain early born neurons, which display early mature synaptic connections (Mitrofanis and Guillery, 1993; Molnár and Cordery, 1999; Cruikshank et al., 2010). Given the importance of transient circuits involving the subplate, we propose transient circuits comprising corticothalamic axons, PRN and RTN neurons and the thalamus may shape mature corticothalamic connections.

Anatomical tracing confirms that corticofugal axons project to the RTN and reticular neurons project to the thalamus prior to corticothalamic axons invading thalamic nuclei (Mitrofanis and Baker, 1993; Molnár et al., 1998a; Molnár and Cordery, 1999). Optical recording using voltage sensitive dyes demonstrate functional excitatory synapses between the cortex and RTN in early postnatal rat (Figure 8). This circuit may also contribute to the depolarization seen in the ventroposterior lateral thalamic nucleus (VPL) at this age, although with this method it is difficult to distinguish between direct cortical and indirect RTN activation of the VPL. In the adult the RTN to thalamus circuit, unlike the subplate circuit, is a substrate for feedforward and feedback inhibition to the relay cells of the thalamus (Guillery and Sherman, 2002; Jones, 2002). Immediately after birth GABAergic IPSCs are recorded in mouse thalamic relay cells in response to reticular neuron activity. This inhibitory innervation increases over early postnatal weeks although adult properties are not fully established until P9 (Warren and Jones, 1997; Warren et al., 1997; Evrard and Ropert, 2009). Thus at birth the circuit is already exhibiting adult features.

However the embryonic connectivity has not been studied and may mimic the subplate's feedforward excitation to strengthen corticothalamic connections. Indeed the RTN axons are the first to innervate the thalamus - at E14 in rats. This is days before peripheral and cortical inputs (cortical innervation arrives 3 days later at E17) thus suggesting an important developmental role of the RTN-thalamic connectivity (Mitrofanis and Guillery, 1993). 

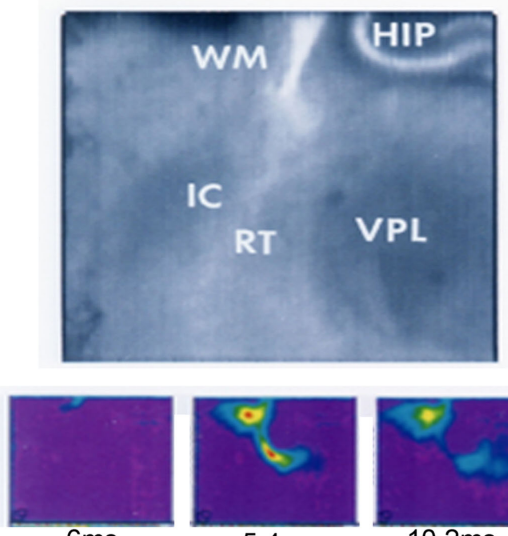

$5.4 \mathrm{~ms}$

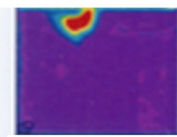

$1.8 \mathrm{~ms}$

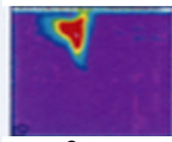

$3 \mathrm{~ms}$

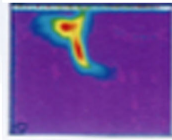

$4.2 \mathrm{~ms}$

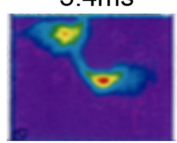

$6.6 \mathrm{~ms}$

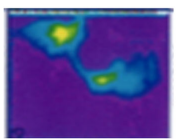

$7.8 \mathrm{~ms}$

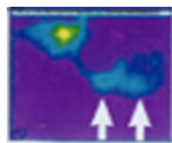

$9 \mathrm{~ms}$

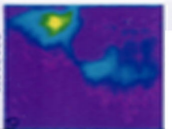

$10.2 \mathrm{~ms}$

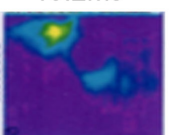

$11.4 \mathrm{~ms}$

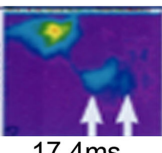

$17.4 \mathrm{~ms}$

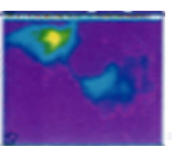

$23.4 \mathrm{~ms}$

FIGURE 8 | Functional synapses revealed in the reticular thalamic nucleus after cortical stimulation in a thalamocortical slice from a P2 rat. A thalamocortical slice was prepared and stained with voltage sensitive dye RH482 according to the protocols previously described in Higashi et al. (2002, 2005). The slice was positioned to be able to observe the internal capsule, reticular thalamic nucleus (labeled $\mathrm{RT}$ in panels), part of the thalamus (VPL) and hippocampus (HIP). A stimulating electrode was placed into the white matter below the primary somatosensory cortex. Stimulus-induced changes in the intensity of transmitted light $(700 \pm 30 \mathrm{~nm})$ were collected with a $128 \times 128$ pixel array of photosensors $\left(70 \mu \mathrm{m}^{2} /\right.$ pixel) every $0.6 \mathrm{~ms}$ (Fujifilm HR Deltaron 1700, Japan) for up to $300 \mathrm{~ms}$ (each pixel measured the change in
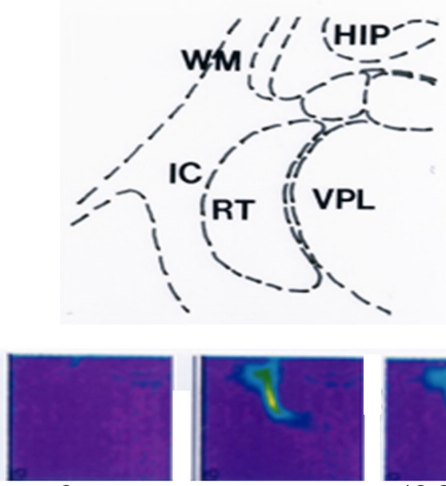

$.6 \mathrm{~ms}$

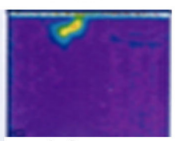

$1.8 \mathrm{~ms}$

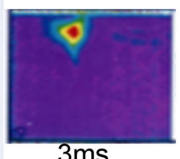

$5.4 \mathrm{~ms}$

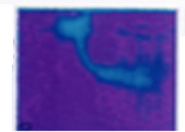

$10.2 \mathrm{~ms}$
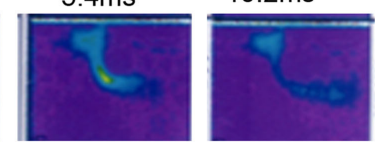

$6.6 \mathrm{~ms}$

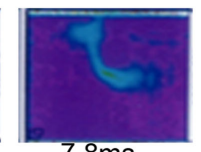

$11.4 \mathrm{~ms}$

3ms

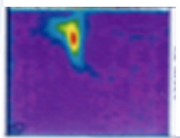

$4.2 \mathrm{~ms}$

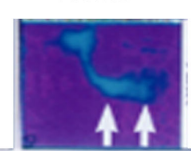

$9 \mathrm{~ms}$

transmitted light intensity relative to a prestimulus reference image acquired just before the recording trial). The selected frames on the left record the response to stimulation after $0.6,1.8,3,4.2,5.4,6.6,7.8,9,10.2,11.4,17.4$, and $23.4 \mathrm{~ms}$; on the right the same frames are presented after the application of $40 \mu \mathrm{M}$ 6,7-dinitroquinoxaline-2,3-dione (DNOX, Tocris, UK) and $50 \mu \mathrm{M}$ 2-amino-5-phosphonopentanoic acid (APV, Sigma, USA) for 20-30 min. Sustained depolarization was observed in RTN and VPL in controls which was reduced after the DNQX and APV application, activity in RTN and VPL indicated by arrows in frames recorded at 9 and $17.4 \mathrm{~ms}$ in left and right frames. HIP, hippocampus; RTN, reticular thalamic nucleus; VPL, ventro-posterior lateral thalamic nucleus.

Such questions concerning how cortical axons initially integrate into thalamic circuits and what role the RTN contributes will be important in the coming years. The answers may be critical in our understanding of how the developmental process may go awry in pathologies of connectivity.

\section{CONCLUSION}

Classic anatomical research has elucidated the tightly scheduled timing and specificity of the development of corticothalamic axons. This research demonstrates how the complexity of the corticothalamic connection requires highly specific and combinatorial use of guidance mechanisms during development. From the start of their journey corticothalamic axons are encountering cell type specific molecular cues which guide them out of the cortex, along the intermediate zone, across the internal capsule and into the thalamus. They must respond to structural cues as they traverse developmental compartments at the PSPB and DTB which may direct gene-expression changes. Then as they reach the prethalamus the axons interact with intermediate cellular populations including the perireticular/corridor cells and the RTN cells perhaps gaining both guidance instructions and integrating into transient developmental circuits.

However there are still unresolved questions which we propose lie in three key areas. Firstly cortical cell subpopulations must be regarded separately, distinguishing layers 5, 6 and subplate and subpopulations within layers, rather than gathering fibers into heterogeneous groups which will likely have different cues. This will enable the next level of detail in understanding the development of highly complex circuits. Secondly research must probe the cellular and molecular identities of the telencephalic and diencephalic regions that corticothalamic axons encounter and how this compartmental environment is important for corticothalamic guidance. Thirdly work must look more closely at developmental circuitry including the details of transient circuitry and the balance between intrinsic guidance factors and external inputs. Modern techniques are now being harnessed and 
are starting to yield results, including reporter gene expressing transgenic mouse lines and conditional knock-out mice, in utero electroporation and the recent availability of population specific markers. These models could be further exploited after sensory alterations and during cross-modal plasticity in order to probe the role of external input in generating highly specific corticothalamic circuits. Understanding the logic of development of the cortical input to thalamus is integral to the compre-

\section{REFERENCES}

Adams, N. C., Lozsádi, D. A., and Guillery, R. W. (1997). Complexities in the thalamocortical and corticothalamic pathways. Eur. J. Neurosci. 9, 204-209.

Agmon, A., Yang, L. T., Jones, E. G., and O’Dowd, D. K. (1995). Topological precision in the thalamic projection to neonatal mouse barrel cortex. $J$. Neurosci. 15, 549-561.

Allendoerfer, K. L., and Shatz, C. J. (1994). The subplate, a transient neocortical structure: its role in the development of connections between thalamus and cortex. Annu. Rev. Neurosci. 17, 185-218.

Andrews, W., Liapi, A., Plachez, C., Camurri, L., Zhang, J., Mori, S., Murakami, F., Parnavelas, J. G., Sundaresan, V., and Richards, L. J. (2006). Robol regulates the development of major axon tracts and interneuron migration in the forebrain. Development 133, 2243-2252.

Auladell, C., Perez-Sust, P., Super, H., and Soriano, E. (2000). The early development of thalamocortical and corticothalamic projections in the mouse. Anat. Embryol. 201, 169-179.

Bagnard, D., Chounlamountri, N., Puschel, A. W., and Bolz, J. (2001). Axonal surface molecules act in combination with semaphorin $3 \mathrm{a}$ during the establishment of corticothalamic projections. Cereb. Cortex 11, 278-285.

Bagnard, D., Lohrum, M., Uziel, D., Puschel, A. W., and Bolz, J. (1998). Semaphorins act as attractive and repulsive guidance signals during the development of cortical projections. Development 125, 5043-5053.

Bagnard, D., Thomasset, N., Lohrum, M., Puschel, A. W., and Bolz, J. (2000). Spatial distributions of guidance molecules regulate chemorepulsion and chemoattraction of growth cones. J. Neurosci. 20, 1030-1035.

Bagri, A., Marín, O., Plump, A. S., Mak, J., Pleasure, S. J., Rubenstein, J. L. R., and Tessier-Lavigne, M. (2002). Slit proteins prevent midline crossing and determine the dorsoventral position of major axonal pathways in the mammalian forebrain. Neuron $33,233-248$.
Behrens, T. E., Johansen-Berg, H., Woolrich, M. W., Smith, S. M., WheelerKingshott, C. A., Boulby, P. A., Barker, G. J., Sillery, E. L., Sheehan, K., Ciccarelli, O., Thompson, A. J., Brady, J. M., and Matthews, P. M. (2003). Non-invasive mapping of connections between human thalamus and cortex using diffusion imaging. Nat. Neurosci. 6, 750-757.

Bernardo, K. L., and Woolsey, T. A. (1987). Axonal trajectories between mouse somatosensory thalamus and cortex. J. Comp. Neurol. 258, 542-564.

Bicknese, A. R., Sheppard, A. M., O'Leary, D. D., and Pearlman, A. L. (1994). Thalamocortical axons extend along a chondroitin sulfate proteoglycan-enriched pathway coincident with the neocortical subplate and distinct from the efferent path. J. Neurosci. 14, 3500-3510.

Blakemore, C., and Molnar, Z. (1990). ment of specific interconnections between thalamus and cerebral cortex. Cold Spring Harb. Symp. Quant. Biol. 55, 491-504.

Blakey, D., Wilson, C., Molnár, Z. (2012). Development of thalamocortical arbors in the absence of regulated synaptic vesicle release, a study in thalamocortical coculture of Snap25 KO mouse. Eur. J. Neurosci. doi: 10.1111/j.14609568.2012.08120.x

Braisted, J. E., Catalano, S. M., Stimac, R., Kennedy, T. E., Tessier-Lavigne, M., Shatz, C. J., and O'Leary, D. D. M. (2000). Netrin-1 promotes thalamic axon growth and is required for proper development of the thalamocortical projection. J. Neurosci. 20, 5792-5801.

Braisted, J. E., Ringstedt, T., and O'Leary, D. D. M. (2009). Slits are chemorepellents endogenous to hypothalamus and steer thalamocortical axons into ventral telencephalon. Cereb. Cortex 19, i144-i151.

Carney, R. S., Alfonso, T. B., Cohen, D., Dai, H., Nery, S., Stoica, B., Slotkin, J., Bregman, B. S., Fishell, G., and Corbin, J. G. (2006). Cell migration along the lateral cortical stream to the developing basal Factors involved in the establish-

hension of the function of the thalamus and corticothalamic circuits.

\section{ACKNOWLEDGMENTS}

We thank Ray Guillery and John Mitrofanis for their thoughtful comments on earlier drafts of this review. Work in Zoltán Molnár's laboratory is supported by Medical Research Council, The Wellcome Trust, EU and BBSRC.

telencephalic limbic system. J. Neurosci. 26, 11562-11574.

Carney, R. S. E., Cocas, L. A., Hirata, T., Mansfield, K., and Corbin, J. G. (2009). Differential regulation of telencephalic pallial-subpallial boundary patterning by Pax6 and Gsh2. Cereb. Cortex 19, 745-759.

Catalano, S. M., and Shatz, C. J. (1998). Activity-dependent cortical target selection by thalamic axons. Science 281, 559-562.

Caviness, V. S. Jr., and Frost, D. O. (1980). Tangential organization of thalamic projections to the neocortex in the mouse. J. Comp. Neurol. 194, 335-367.

Chen, Y., Magnani, D., Theil, T., Pratt, T., and Price, D. J. (2012). Evidence that descending cortical axons are essential for thalamocortical axons to cross the pallial-subpallial boundary in the embryonic forebrain. PLoS ONE 7, e33105. doi:10.1371/journal.pone. 0033105

Clascá, F., Angelucci, A., and Sur, M. (1995). Layer-specific programs of development in neocortical projection neurons. Proc. Natil. Acad. Sci. U.S.A. 92, 11145-11149.

Connolly, M., and Van Essen, D. (1984). The representation of the visual field in parvicellular and magnocellular layers of the lateral geniculate nucleus in the macaque monkey. $J$. Comp. Neurol. 226, 544-564.

Cruikshank, S. J., Urabe, H., Nurmikko, A. V., and Connors, B. W. (2010). Pathway-specific feedforward circuits between thalamus and neocortex revealed by selective optical stimulation of axons. Neuron 65, 230-245.

De Carlos, J., and O’Leary, D. (1992). Growth and targeting of subplate axons and establishment of major cortical pathways [published erratum appears in J Neurosci 1993 Mar;13(3):following table of contents]. J. Neurosci. 12, 1194-1211.

Diamond, I. T., Jones, E. G., and Powell, T. P. (1969). The projection of the auditory cortex upon the diencephalon and brain stem in the cat. Brain Res. 15, 305-340.

Evrard, A., and Ropert, N. (2009). Early development of the thalamic inhibitory feedback loop in the primary somatosensory system of the newborn mice. J. Neurosci. 29, 9930-9940.

Fishell, G., and Hanashima, C. (2008). Pyramidal neurons grow up and change their mind. Neuron 57, 333-338.

Frost, D. O., and Caviness, V. S. Jr. (1980). Radial organization of thalamic projections to the neocortex in the mouse. J. Comp. Neurol. 194, 369-393.

Garel, S., and Rubenstein, J. L. R. (2004). Intermediate targets in formation of topographic projections: inputs from the thalamocortical system. Trends Neurosci. 27, 533-539.

Ghosh, A., Antonini, A., McConnell, S. K., and Shatz, C. J. (1990). Requirement for subplate neurons in the formation of thalamocortical connections. Nature 347, 179-181.

Grant, E. G., and Molnar, Z. (2012). "Lack of effect of early sensory input on development of the corticothalamic connection," in Poster presentation for The 8th FENS Forum of Neuroscience, Barcelona.

Guillery, R. W. (1967). Patterns of fiber degeneration in the dorsal lateral geniculate nucleus of the cat following lesions in the visual cortex. $J$. Comp. Neurol. 130, 197-221.

Guillery, R. W. (1995). Anatomical evidence concerning the role of the thalamus in corticocortical communication: a brief review. J. Anat. 187(Pt 3), 583-592.

Guillery, R. W., and Sherman, S. M. (2002). Thalamic relay functions and their role in corticocortical communication: generalizations from the visual system. Neuron 33, 163-175.

Hanashima, C., Molnár, Z., and Fishell, G. (2006). Building bridges to the cortex. Cell 125, 24-27.

Hevner, R. F., Miyashita-Lin, E., and Rubenstein, J. L. R. (2002). Cortical and thalamic axon pathfinding defects in Tbr1, Gbx2, and Pax6 mutant mice: evidence that cortical and thalamic axons interact and guide each other. J. Comp. Neurol. 447, 8-17.

Higashi, S., Hioki, K., Kurotani, T., and Molnár, Z. (2005). Functional thalamocortical synapse reorganization 
from subplate to layer IV during postnatal development in the reeler-like mutant rat (Shaking rat Kawasaki): an optical recording study. J. Neurosci. 25, 1395-1406.

Higashi, S., Molnár, Z., Kurotani, T., Inokawa, H., and Toyama, K. (2002). Functional thalamocortical connections develop during embryonic period in the rat: an optical recording study. Neuroscience 115, 1231-1246.

Hoerder-Suabedissen, A., and Molnár, Z. (2012a). Morphology of mouse subplate cells with identified projection targets changes with age. $J$. Comp. Neurol. 520, 174-185.

Hoerder-Suabedissen, A., and Molnár, Z. (2012b). Early-born subplate neurons are molecularly diverse. Cereb. Cortex (in press).

Hoerder-Suabedissen, A., Wang, W. Z., Lee, S., Davies, K. E., Goffinet, A. M., Rakic, S., Parnavelas, J., Reim, K., Nicolic, M., Paulsen, O., and Molnar, Z. (2009). Novel markers reveal subpopulations of subplate neurons in the murine cerebral cortex. Cereb. Cortex 19, 1738-1750.

Hoogland, P. V., Welker, E., and Van der Loos, H. (1987). Organization of the projections from barrel cortex to thalamus in mice studied with Phaseolus vulgaris-leucoagglutinin and HRP. Exp. Brain Res. 68, 73-87.

Horng, S., Kreiman, G., Ellsworth, C., Page, D., Blank, M., Millen, K., and Sur, M. (2009). Differential gene expression in the developing lateral geniculate nucleus and medial geniculate nucleus reveals novel roles for Zic4 and Foxp2 in visual and auditory pathway development. J. Neurosci. 29, 13672-13683.

Hubel, D. H., and Wiesel, T. N. (1977). Ferrier lecture. Functional architecture of macaque monkey visual cortex. Proc. R. Soc. Lond. B Biol. Sci. 198, 1-59.

Jacobs, E. C., Campagnoni, C., Kampf, K., Reyes, S. D., Kalra, V., Handley, V., Xie, Y. Y., Hong-Hu, Y., Spreur, V., Fisher, R. S., and Campagnoni, A. T. (2007). Visualization of corticofugal projections during early cortical development in a tau-GFP-transgenic mouse. Eur. J. Neurosci. 25, 17-30.

Jones, E. G. (1985). The Thalamus. New York: Plenum Press.

Jones, E. G. (2002). Thalamic circuitry and thalamocortical synchrony. Philos. Trans. R. Soc. Lond. B Biol. Sci. 357, 1659-1673.

Jones, E. G., and Powell, T. P. (1968). The projection of the somatic sensory cortex upon the thalamus in the cat. Brain Res. 10, 369-391.
Jones, L., López-Bendito, G., Gruss, P., Stoykova, A., and Molnár, Z. (2002). Pax6 is required for the normal development of the forebrain axonal connections. Development 129 , 5041-5052.

Kaas, J. H. (2007). "The evolution of the dorsal thalamus in mammals," in Evolution of Nervous Systems: A Comprehensive Reference, Vol. 3, Chap. 35, eds J. H. Kaas and L. A. Krubitzer (Amsterdam: Elsevier Academic Press), 499-516.

Kanold, P. O., Kara, P., Reid, R. C., and Shatz, C. J. (2003). Role of subplate neurons in functional maturation of visual cortical columns. Science 301, 521-525.

Kanold, P. O., and Luhmann, H. J. (2010). The subplate and early cortical circuits. Annu. Rev. Neurosci. 33, 23-48.

Kanold, P. O., and Shatz, C. J. (2006). Subplate neurons regulate maturation of cortical inhibition and outcome of ocular dominance plasticity. Neuron 51, 627-638.

Kostovic, I., and Rakic, P. (1990). Developmental history of the transient subplate zone in the visual and somatosensory cortex of the macaque monkey and human brain. J. Comp. Neurol. 297, 441-470.

Lett, R. L. M., Wang, W., and O'Connor, T. P. (2009). Semaphorin $5 B$ is a novel inhibitory cue for corticofugal axons. Cereb. Cortex 19, 1408-1421.

Lickiss, T., Cheung, A. F., Hutchinson, C. E., Taylor, J. S., and Molnar, Z. (2012). Examining the relationship between early axon growth and transcription factor expression in the developing cerebral cortex. J. Anat. 220, 201-211.

López-Bendito, G., Cautinat, A., Sánchez, J. A., Bielle, F., Flames, N., Garratt, A. N., Talmage, D. A., Role, L. W., Charnay, P., Marín, O., and Garel, S. (2006). Tangential neuronal migration controls axon guidance: a role for Neuregulin-1 in thalamocortical axon navigation. Cell 125, 127-142.

López-Bendito, G., Flames, N., Ma, L., Fouquet, C., Di Meglio, T., Chedotal, A., Tessier-Lavigne, M., and Marín, O. (2007). Robol and Robo2 cooperate to control the guidance of major axonal tracts in the mammalian forebrain. $J$. Neurosci. 27, 3395-3407.

López-Bendito, G., and Molnar, Z. (2003). Thalamocortical development: how are we going to get there? Nat. Rev. Neurosci. 4, 276-289.

Lozsádi, D. A., Gonzalez-Soriano, J., and Guillery, R. W. (1996). The course and termination of corticothalamic fibres arising in the visual cortex of the rat. Eur. J. Neurosci. 8, 2416-2427.

McConnell, S., Ghosh, A., and Shatz, C. (1994). Subplate pioneers and the formation of descending connections from cerebral cortex. J. Neurosci. 14, 1892-1907.

McConnell, S. K., Ghosh, A., and Shatz, C. J. (1989). Subplate neurons pioneer the first axon pathway from the cerebral cortex. Science 245 978-982.

Métin, C., Deleglise, D., Serafini, T., Kennedy, T. E., and Tessier-Lavigne, M. (1997). A role for netrin-1 in the guidance of cortical efferents. Development 124, 5063-5074.

Miller, B., Chou, L., and Finlay, B. L. (1993). The early development of thalamocortical and corticothalamic projections. J. Comp. Neurol. 335, 16-41.

Mitrofanis, J., and Baker, G. E. (1993). Development of the thalamic reticular and perireticular nuclei in rats and their relationship to the course of growing corticofugal and corticopetal axons. J. Comp. Neurol. $338,575-587$.

Mitrofanis, J., and Guillery, R. W. (1993). New views of the thalamic reticular nucleus in the adult and the developing brain. Trends Neurosci. 16, 240-245.

Molnár, Z. (1998). Development of Thalamocortical Connections. Heidelberg: Springer, 264.

Molnár, Z., Adams, R., and Blakemore, C. (1998a). Mechanisms underlying the early establishment of thalamocortical connections in the rat. $J$. Neurosci. 18, 5723-5745.

Molnár, Z., Adams, R., Goffinet, A., and Blakemore, C. (1998b). The role of the first postmitotic cortical cells in the development of thalamocortical innervation in the Reeler mouse. $J$. Neurosci. 18, 5746-5765.

Molnár, Z., and Blakemore, C. (1995). How do thalamic axons find their way to the cortex? Trends Neurosci. 18, 389-397.

Molnár, Z., and Cheung, A. F. P. (2006). Towards the classification of subpopulations of layer $\mathrm{V}$ pyramidal projection neurons. Neurosci. Res. 55, 105-115.

Molnár, Z., and Cordery, P. (1999). Connections between cells of the internal capsule, thalamus, and cerebral cortex in embryonic rat. $J$. Comp. Neurol. 413, 1-25.

Molnár, Z., Garel, S., López-Bendito, G., Maness, P., and Price, D. J. (2012). Mechanisms controlling the guidance of thalamocortical axons through the embryonic forebrain. Eur. J. Neurosci. doi: 10.1111/j.1460-9568.2012.08119.x

Molnár, Z., Lopez-Bendito, G., Small, J., Partridge, L. D., Blakemore, C. and Wilson, M. C. (2002). Normal development of embryonic thalamocortical connectivity in the absence of evoked synaptic activity. J. Neurosci. 22, 10313-10323.

Molyneaux, B. J., Arlotta, P., Menezes, J. R., and Macklis, J. D. (2007). Neuronal subtype specification in the cerebral cortex. Nat. Rev. Neurosci. 8, 427-437.

Montiel, J. F., Wang, W. Z., Oeschger, F. M., Hoerder-Suabedissen, A., Tung, W. L., Garcia Moreno, F., Holm, I. E., Villalón, A., and Molnar, Z. (2011). Hypothesis on the dual origin of the mammalian subplate. Front. Neuroanat. 5:25. doi:10.3389/fnana.2011.00025

Nelson, S. B., and LeVay, S. (1985). Topographic organization of the optic radiation of the cat. J. Comp. Neurol. 240, 322-330.

Noctor, S. C., Martinez-Cerdeno, V., Ivic, L., and Kriegstein, A. R. (2004). Cortical neurons arise in symmetric and asymmetric division zones and migrate through specific phases. Nat. Neurosci. 7, 136-144.

Oeschger, F. M., Wang, W.-Z., Lee, S., García-Moreno, F., Goffinet, A. M., Arbonés, M. L., Rakic, S., and Molnár, Z. (2011). Gene expression analysis of the embryonic subplate. Cereb. Cortex. doi: 10.1093/cercor/bhr197. [Epub ahead of print].

Piñon, M. C., Jacobs, E., Campagnoni, A., and Molnar, Z. (2005). "Development of the cortical projections from subplate neurons to the thalamus in Golli-tau-eGFP transgenic mice", in BNA, Brighton, Abstract 3.05.

Piñon, M. C., Jethwa, A., Jacobs, E., Campagnoni, A., and Molnar, Z. (2009). Dynamic integration of subplate neurons into the cortical barrel field circuitry during postnatal development in the Golli-tau-eGFP (GTE) mouse. J. Physiol. 587, 1903-1915.

Piñon, M. C., Tuoc, T. C., AsheryPadan, R., Molnár, Z., and Stoykova, A. (2008). Altered molecular regionalization and normal thalamocortical connections in cortex-specific Pax6 knock-out mice. J. Neurosci. 28, 8724-8734.

Polleux, F., Morrow, T., and Ghosh, A. (2000). Semaphorin $3 \mathrm{~A}$ is a chemoattractant for cortical apical dendrites. Nature 404, 567-573.

Price, D. J., Aslam, S., Tasker, L., and Gillies, K. (1997). Fates of the earliest generated cells in the developing 
murine neocortex. J. Comp. Neurol. 377, 414-422.

Price, D. J., Clegg, J. M., Oliver Duocastella, X., Willshaw, D. J., and Pratt, T. (2012). The importance of combinatorial gene expression in early mammalian thalamic patterning and thalamocortical axonal guidance. Front. Neurosci. 6:37. doi:10.3389/fnins.2012.00037

Puelles, L., Kuwana, E., Puelles, E., Bulfone, A., Shimamura, K., Keleher, J., Smiga, S., and Rubenstein, J. L. R. (2000). Pallial and subpallial derivatives in the embryonic chick and mouse telencephalon, traced by the expression of the genes Dlx-2, Emx-1, Nkx-2.1, Pax-6, and Tbr-1. J. Comp. Neurol. 424, 409-438.

Rakic, P. (1976). Prenatal genesis of connections subserving ocular dominance in the rhesus monkey. Nature 261, 467-471.

Richards, L. J., Koester, S. E., Tuttle, R., and O'Leary, D. D. M. (1997). Directed growth of early cortical axons is influenced by a chemoattractant released from an intermediate target. J. Neurosci. 17, 2445-2458.

Rosa, M. G., Casagrande, V. A., Preuss, T., and Kaas, J. H. (1997). Visual field representation in striate and prestriate cortices of a prosimian primate (Galago garnetti). J. Neurophysiol. 77, 3193-3217.

Rouiller, E. M., and Welker, E. (2000). A comparative analysis of the morphology of corticothalamic projections in mammals. Brain Res. Bull. 53, 727-741.

Schuurmans, C., and Guillemot, F. (2002). Molecular mechanisms underlying cell fate specification in the developing telencephalon. Curr. Opin. Neurobiol. 12, 26-34.

Shatz, C. J., and Rakic, P. (1981). The genesis of efferent connections from the visual cortex of the fetal rhesus monkey. J. Comp. Neurol. 196, 287-307.

Sherman, S. M., and Guillery, R. W. (1998). On the actions that one nerve cell can have on another: distinguishing "drivers" from "modulators”. Proc. Natil. Acad. Sci. U.S.A. 95, 7121-7126.

Sherman, S. M., and Guillery, R. W. (2002). The role of the thalamus in the flow of information to the cortex. Philos. Trans. R. Soc. Lond. B Biol. Sci. 357, 1695-1708.

Shimogori, T., and Grove, E. A. (2005). Fibroblast growth factor 8 regulates neocortical guidance of area-specific thalamic innervation. J. Neurosci. 25, 6550-6560.

Simeone, A., Acampora, D., Gulisano, M., Stornaiuolo, A., and Boncinelli, E. (1992). Nested expression domains of four homeobox genes in developing rostral brain. Nature 358, 687-690.

Skaliora, I., Singer, W., Betz, H., and Puschel, A. W. (1998). Differential patterns of semaphorin expression in the developing rat brain. Eur. J. Neurosci. 10, 1215-1229.

Steriade, M. (2000). Corticothalamic resonance, states of vigilance and mentation. Neuroscience 101, 243-276.

Stoykova, A., and Gruss, P. (1994). Roles of Pax-genes in developing and adult brain as suggested by expression patterns. J. Neurosci. 14, 1395-1412.

Tolner, E. A., Sheikh, A., Yukin, A. Y., Kaila, K., and Kanold, P. O. (2012). Subplate neurons promote spindle bursts and thalamocortical patterning in the neonatal rat somatosensory cortex. J. Neurosci. 32, 692-702.

Wang, W. Z., Oeschger, F. M., Montiel, J. F., Garcia-Moreno, F., HoerderSuabedissen, A., Krubitzer, L., Ek, C. J., Saunders, N. R., Reim, K. Villalon, A., and Molnar, Z. (2011). Comparative aspects of subplate zone studied with gene expression in sauropsids and mammals. Cereb. Cortex 21, 2187-2203.

Warren, R. A., Golshani, P., and Jones, E. G. (1997). GABABreceptor-mediated inhibition in developing mouse ventral posterior thalamic nucleus. J. Neurophysiol. 78, 550-553.

Warren, R. A., and Jones, E. G. (1997) Maturation of neuronal form and function in a mouse thalamocortical circuit. J. Neurosci. 17, 277-295.

Washbourne, P., Thompson, P. M., Carta, M., Costa, E. T., Mathews, J. R., Lopez-Bendito, G., Molnar, Z., Becher, M. W., Valenzuela, C. F., Partridge, L. D., and Wilson, M. C. (2002). Genetic ablation of the t-SNARE SNAP-25 distinguishes mechanisms of neuroexocytosis. Nat. Neurosci. 5, 19-26.

Watanabe, K., Tamamaki, N., Furuta, T., Ackerman, S. L., Ikenaka, K., and Ono, K. (2006). Dorsally derived Netrin 1 provides an inhibitory cue and elaborates the 'waiting period' for primary sensory axons in the developing spinal cord. Development 133, 1379-1387.

Zhao, C., Kao, J. P. Y., and Kanold, P. O. (2009). Functional excitatory microcircuits in neonatal cortex connect thalamus and layer 4. J. Neurosci. 29, 15479-15488.

Zhou, L., Bar, I., Achouri, Y., Campbell, K., De Backer, O., Hebert, J. M., Jones, K., Kessaris, N., de Rouvroit, C. L., O'Leary, D., Richardson, W. D., Goffinet, A. M., and Tissir, F. (2008). Early forebrain wiring: genetic dissection using conditional Celsr3 mutant mice. Science 320 , 946-949.

Zhou, L., Qu, Y., Tissir, F., and Goffinet, A. M. (2009). Role of the atypical cadherin Celsr3 during development of the internal capsule. Cereb. Cortex 19, i114-i119.

Conflict of Interest Statement: The authors declare that the research was conducted in the absence of any commercial or financial relationships that could be construed as a potential conflict of interest.

Received: 01 February 2012; paper pending published: 16 February 2012; accepted: 29 March 2012; published online: 04 May 2012.

Citation: Grant E, Hoerder-Suabedissen $A$ and Molnár Z (2012) Development of the corticothalamic projections. Front. Neurosci. 6:53. doi: 10.3389/fnins.2012.00053

This article was submitted to Frontiers in Neurogenesis, a specialty of Frontiers in Neuroscience.

Copyright (c) 2012 Grant, HoerderSuabedissen and Molnár. This is an open-access article distributed under the terms of the Creative Commons Attribution Non Commercial License, which permits non-commercial use, distribution, and reproduction in other forums, provided the original authors and source are credited. 